\title{
Restoring lepidopteran diversity in a tropical dry forest: relative importance of restoration treatment, tree identity and predator pressure
}

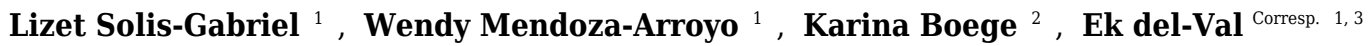 \\ 1 Instituto de Investigaciones en Ecosistemas y Sustentabilidad, Universidad Nacional Autónoma de México, Morelia, Michoacán, Mexico \\ 2 Insituto de Ecología, Universidad Nacional Autónoma de México, Ciudad de México, A.P. 20-275. Ciudad Universitaria, C.P. 04510,, Mexico \\ 3 Escuela Nacional de Estudios Superiores Unidad Morelia, Universidad Nacional Autónoma de México, Morelia, Michoacán, Mexico \\ Corresponding Author: Ek del-Val \\ Email address: ekdelval@iies.unam.mx
}

Tropical dry forests have been widely transformed by human activities worldwide and the ecosystem services they provide are diminishing. There has been an urgent call for conservation and restoration of the degraded lands previously occupied by TDFs. Restoration experiences aim to recover species diversity and ecological functions. Different restoration strategies have been used to maximize plant performance including weeding, planting or using artificial mulching. In this investigation, we evaluated whether different restoration practices influence animal arrival and the reestablishment of biotic interactions. We particularly evaluated lepidopteran larvae diversity and caterpillar predation on plants established under different restoration treatments (mulching, weeding and control) in the Pacific West Coast of México. This study corroborated the importance of plant host identity for lepidopteran presence in a particular area. Lepidopteran diversity and herbivory rates were not affected by the restoration treatment but they were related with tree species. In contrast, caterpillar predation marks were affected by restoration treatment, with greater number of predation marks in control plots, while caterpillar predation marks among plant species were not significantly different. This study highlights the importance of considering the introduction of a high plant species diversity when planning tropical dry forest restoration, to maximize lepidopteran diversity and ecosystem functioning. 
1 Restoring lepidopteran diversity in a tropical dry forest: relative importance of restoration

2 treatment, tree identity and predator pressure.

3 Lizet Solis-Gabriel ${ }^{1}$, Wendy Mendoza-Arroyo ${ }^{1}$, Karina Boege ${ }^{2}$, Ek del-Val ${ }^{1,3}$

$4 \quad{ }^{1}$ Instituto de Investigaciones en Ecosistemas y Sustentabilidad, Universidad Nacional Autónoma

5 de México, Antigua Carretera a Pátzcuaro No. 8701, Col. Ex-Hacienda de San José de La Huerta,

6 C.P. 58190, Morelia, Michoacán, México

7 Instituto de Ecología, Universidad Nacional Autónoma de México, Circuito Exterior S/N,

8 Ciudad Universitaria, C.P. 04510, Ciudad de México, México

$9{ }^{3}$ Escuela Nacional de Estudios Superiores Unidad Morelia, Universidad Nacional Autónoma de

10 México, Antigua Carretera a Pátzcuaro No. 8701, Col. Ex-Hacienda de San José de La Huerta,

11 C.P. 58190, Morelia, Michoacán, México

12 *Corresponding author: Ek del-Val, ekdelval@cieco.unam.mx 
13 Abstract

14 Tropical dry forests (TDFs) have been widely transformed by human activities worldwide and the 15 ecosystem services they provide are diminishing. There has been an urgent call for conservation 16 and restoration of the degraded lands previously occupied by TDFs. Restoration aims to recover

17 species diversity and ecological functions. Different restoration strategies have been used to 18 maximize plant performance including weeding, planting or using artificial mulching. In this 19 investigation, we evaluated whether different restoration practices influence animal arrival and

20 the reestablishment of biotic interactions. We particularly evaluated diversity of lepidopteran

21 larvae and model caterpillar predation on plants established under different restoration treatments 22 (mulching, weeding and control) in the Pacific West Coast of México. This study corroborated 23 the importance of plant host identity for lepidopteran presence in a particular area. Lepidopteran 24 diversity and herbivory rates were not affected by the restoration treatment, but they were related 25 to tree species. In contrast, predation marks on clay caterpillars placed on trees were affected by 26 restoration treatment, with a greater number of predation marks in control plots, while caterpillar 27 predation marks among plant species were not significantly different. This study highlights the 28 importance of considering the introduction of a high plant species diversity when planning 29 tropical dry forest restoration, in order to maximize lepidopteran diversity and ecosystem 30 functioning.

31 Introduction

32 Ecological restoration aims to recover species diversity and ecological functions (SER 2007, 33 Howe and Martínez-Garza 2014). Different restoration strategies have been used to maximize 34 plant survival and performance including weeding, planting or using artificial mulching. In 35 general treatments that enhance soil water content and minimize competition with background vegetation are the ones showing better results for plant performance (Chalker-Scott 2007, Barajas-Guzmán and Barradas 2011). However, when considering other aspects for restoring ecological functions such as the arrival of primary and secondary consumers, very few investigations have evaluated different restoration treatments. The recovery of animal populations

40 is fundamental for restoring ecological functions (Noreika et al. 2015, Jones and Davidson 2016).

41 Therefore, there is a need to understand if differences in vegetation performance due to different

42 restoration treatments are translated into animal communities and further into ecological 43 functioning. 
44 Lepidopterans are an important group of invertebrates in tropical forests because they are a very

45 diverse group and function as herbivores when larvae and pollinators as adults. As herbivores

46 they consume significant quantities of leaf tissue (Novotny et al. 2002, Novotny et al. 2004,

47 Novotny et al. 2006, Dyer et al. 2007) and as moths and butterflies account for the pollination of

48 at least $10 \%$ of plant species in tropical dry forests (Haber and Frankie 1989). Therefore, when

49 considering the restoration of ecosystems, lepidopterans are group that should be considered

50 since they can help safeguard plant reproduction. Also, lepidopterans represent a significant food

51 source for predators in these forests so are needed to restore the insectivore community.

52 Tropical dry forests (TDF) are one of the most important vegetation types in Latin America.

53 They used to cover 50\% of land (Murphy and Lugo 1986, Sánchez-Azofeifa et al. 2005). In

54 Mexico in particular they covered $37 \%$ of the country, however due to anthropogenic activities

55 such as agriculture and cattle farming (Trejo and Dirzo 2000), only 30\% of the original area

56 remains pristine. The current scenario involves a mosaic of large areas of degraded lands

57 surrounded by secondary forests and few federal and state preserves (Sánchez-Azofeifa et al.

58 2009). Therefore, there is an urgent need to restore degraded lands to conserve ecological

59 functions and guarantee ecosystem services (Ceccon et al. 2015). Controversies around restoring

60 TDFs have arisen due to their relatively high successional speed. Some authors argue that

61 fencing against cattle should be sufficient to ensure forest recovery while others advocate for

62 active interventions involving planting of native tree species (Aide et al. 2000, Gonzáez-Iturbe et

63 al. 2002, Burgos and Maass 2004, Lebrija-Trejos et al. 2008). Recent investigations have found

64 that fencing against cattle in a TDF of southern Mexico was more important for lepidopteran

65 recovery than planting (Juan-Baeza et al. 2015) however, active planting has been shown a speed

66 up plant regeneration and lepidopteran arrival in other restoration experiences (Hernández et al.

67 2014).

68 With the aim of understanding the relative contributions of different restoration treatments for

69 biodiversity and ecological function recovery, in this paper we investigated whether different

70 restoration treatments in the TDF 1) have differential impacts on lepidopteran communities

71 associated with introduced plants, 2) lead to differences in herbivory rates, and 3) have

72 differential impacts on predation rates on model lepidopteran larvae. 
74 Our experimental area is situated in the central Pacific coast of Mexico in the surroundings of the

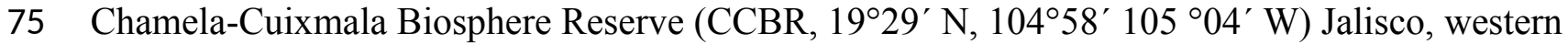
76 Mexico, in pastures formerly covered with tropical dry forests in La Huerta municipality. The main vegetation in the area is tropical dry forest (TDF) with a canopy height between 5 and $10 \mathrm{~m}$, and semi-deciduous forests along riparian zones; dominant plant families are Leguminosae, Euphorbiaceae and Rubiaceae (Lott et al. 1987, Noguera et al. 2002). Mean annual temperature is $24.6^{\circ} \mathrm{C}(1978-2000)$ with a monthly oscillation of $4.3^{\circ} \mathrm{C}$, and mean annual precipitation of 731 $\mathrm{mm}$ (García-Oliva et al. 2002). The rainy season is concentrated from July to November (Noguera et al. 2002) followed by an intense dry season where precipitation is almost $0 \mathrm{~mm}$. The soil types are eutric and lluvieutic regosols, which are highly drained, causing poor water retention (Noguera et al. 2002). The surrounding area of the reserve consists of a mosaic of secondary succession forests, agricultural fields and cattle pastures (Sánchez-Azofeifa et al. 2009). The TDF found at Chamela-Cuixmala is considered one of the most diverse of its kind with 1,200 plant species, comprising a high percentage of endemism (Lott et al. 1987, Trejo and Dirzo 2000). The invertebrate inventory is quite small; however, 1877 invertebrate species have been described, 583 of which are lepidopteran species (Pescador-Rubio et al. 2002).

The restoration area where this investigation took place is located on private land that had been used as cattle pasture for ca. 50 years, but since 2010 the land was put aside for ecological restoration. Ten hectares covered with exotic pastures were restored using 11 native tree species following a blocked experimental design that included three restoration treatments: plastic mulching, weed removal and a control group. Planted species were Cordia alliodora (Ruiz \& Pav.) Oken, Cordia eleagnoides D.C., Caesalpinia eriostachys Benth., Caesalpinia platyloba S. Watson., Caesalpinia pulcherrima, Lysiloma microphylla Benth., Apoplanesia paniculata C. Presl, Leucaena leucocephala (Lam.) de Wit, Guazuma ulmifolia Lam., Gliricidia sepium (Jacq.) Kunth ex Walp.and Heliocarpus pallidus Rose. The treatments were replicated five times in each of five sites with a distance no greater than $1 \mathrm{~km}(\mathrm{~N}=25$ plots; see Saucedo-Morquecho 2016 for experimental details, Fig. 1). Ten individuals oapproximately $1 \mathrm{~m}$ tall of each species were planted in a $30 \times 36 \mathrm{~m}$ plots in a $3 \times 3$ grid $(N=30$ individuals $/$ species/ site/ treatment, a total of 102 4950 plants). To facilitate mycorrhizal colonization, at the time of planting we added ca. $300 \mathrm{gr}$ 
104 to one of the following treatments: i) Plastic mulching, which consisted of covering the soil with

105 an agricultural use plastic before planting, ii) cutting grasses, which consisted of manually

106 removing the vegetation around each sapling every 3 months during one year and iii) no

107 management after planting.

108 Lepidopteran sample

109 In order to assess Lepidoptera larval diversity in the restoration treatments, in 2014, three years

110 after the experimental set up and when plants were $2 \mathrm{~m}$ in height on average (Saucedo-

111 Morquecho 2016), we sampled a subset of the plots under the three legacy experimental

112 treatments in three sites $(N=3$ plots /treatment), including 11 experimental plant species.

113 Sampling was conducted on four plants per tree species $(N=44)$ per plot $(N=396$ plants). During

114 the rainy season of 2014 (July-November) monthly censuses were conducted looking for

115 lepidopteran larvae in all selected plants searching for caterpillars on all leaves and stems. The

116 presence of caterpillars were recorded, and if unknown they were collected, transferred them to

117 the lab and reared into adulthood to further identify the species.

118 Herbivory rates

119 At the end of the rainy season (November), we estimated leaf area consumed by herbivores in

120 five randomly selected mature leaves collected from the same plants used for herbivore censuses.

121 However, only seven species could be assessed as the other four species (L. leucocephala, C.

122 pulcherrima, C. eriostachys and L. microphylla) have very small leaflets in which leaf damage is

123 difficult to assess. Leaves were shade dried and scanned in the laboratory. Leaf area loss was

124 assessed using the program SigmaScan Pro, then we calculated leaf area lost per plant, per

125 species in the different restoration treatments.

126 Caterpillar predation

127 During the rainy season of 2015 we evaluated lepidopteran larvae predation at the same restored

128 sites. In this case, due to time constrains, we used five plants of nine species in only two of the

129 legacy restoration treatments (plastic mulching and control) in two sites (we excluded Cordia

130 alliodora and Leucaena leucocephala because of high mortality during 2015; total sampled

131 plants =180). To infer lepidopteran predation we used artificial clay caterpillar models as

132 proposed by Richards and Coley (2007). Caterpillar models were $3 \mathrm{~cm}$ by $0.5 \mathrm{~cm}$ thick. We used

133 models in bright green and brown-yellow that mimic the most common caterpillar colors in the 
134 region. We decided to use two caterpillar colors since it has been reported that coloration plays an

135 important role in predator behavior and we wanted to test this hypothesis for the TDF. For each

136 experimental plant, we exposed four artificial clay caterpillars (two green a two brown-yellow), a

137 total of 180 caterpillars per restoration treatment per site. Artificial caterpillars were fixed to leaf

138 petioles or abaxial part of leaves using white glue. We exposed caterpillar models to predators for

13924 hours and then we estimated predation by evaluating marks on the clay models. Caterpillars

140 with predation marks were photographed to be analyzed in more detail using a computer.

141 Predation types were assigned following Tvardikova and Novotny (2012) proposal. We repeated

142 the predation experiments four times between July and October 2015, once every month. Missing

143 caterpillars were not included in the analyses since we don't know their final destiny, they

144 accounted for $15 \%$ of clay caterpillar models. Missing caterpillars may have fallen from the trees

145 because the glue was not strong enough of predators may have taken them away.

146 Statistical analysis

147 Lepidopteran richness and abundance was analyzed using nested ANOVAs, with plant species

148 and restoration treatment as the explanatory variables nested by plot/ restoration treatment. To

149 analyze lepidopteran community similarities between plant species and restoration treatments we

150 obtained Bray-Curtis indices per plant species and per treatment, we then plotted the resulting

151 dendrograms showing Bray-Curtis distances and performed a Mantel test with 100 permutations

152 using the "vegan" library to assess the tree significance. Herbivory rates were analyzed using the

153 percent leaf area damaged per plant transformed with arcsin. We also used a nested ANOVA

154 using species and restoration treatment as the explanatory variables nested by plot/ restoration

155 treatment. We also performed a Pearson correlation between herbivory per plant and total

156 lepidopteran abundance. Caterpillar predation was analyzed using a lme (linear mixed effect

157 model) with total percent predation; green caterpillar percent predation and brown caterpillar

158 percent predation as response variables and restoration treatment, with tree species and sampling

159 month as explanatory variables. To analyze differences in predator type we used ANOVA with

160 percent caterpillar predated as a response variable and presumed predator type, caterpillar color,

161 restoration treatment, sampling month and their interactions as explanatory variables. All

162 analyses were performed with $\mathrm{R}$ program version 2.14.0 (R-Core development).

163 Results

164 Lepidopteran diversity 
165 During the 2014 rainy season, we found a total of 234 lepidopteran larvae from 89 species (16

166 identified to species level, 4 to genus and 41 identified to family), 18 species comprised most

167 individuals (44.8\%). Lymantriidae, Psychidae and Crambidae were the best-represented families

168 with 25, 19 and 15 individuals (Fig. 2). Lepidopteran abundance and richness are not affected by

169 the restoration treatment $\left(\mathrm{F}_{(2,42)}=1.22, \mathrm{P}=0.3\right)$ but were related to the particular tree species

170 sampled $\left(\mathrm{F}_{(10,42)}=2.6, \mathrm{P}=0.01\right)$, regardless the restoration treatment (plant species vs. restoration

171 treatment interaction: $\left.\mathrm{F}_{(18,42)}=0.67, \mathrm{P}=0.81\right)$. Many lepidopteran species $(45 \%)$ were present only

172 in one restoration treatment (Table 1) and Bray-Curtis dissimilarity index between restoration

173 treatments was also high ranging from $71 \%$ (control vs. weeding treatment) to $85 \%$ (control vs.

174 mulching treatment). Bray-Curtis dissimilarity index between plant species was very high

175 ranging from $63 \%$ to $100 \%$, suggesting that lepidopteran community composition was influenced

176 by host identity (Table 2). Interestingly, lepidopteran communities associated with the different

177 species of the same genus, such as Caesalpinea or Cordia did not form uniform groups, each

178 Caesalpinea and Cordia species was found in a different branch of the cluster (Suppl. Material

$1791)$.

180 Leaf damage by herbivores

181 Percent leaf area removed per species ranged from 2\% in Apoplanesia paniculata to $12 \%$ in

182 Guazuma ulmifolia and Gliricidia sepium $\left(\mathrm{F}_{(6,36)}=22.7, \mathrm{P}<0.001\right.$; Fig. 3). However, herbivore

183 damage was not different as a function of restoration treatments $\left(\mathrm{F}_{(2,4)}=2.49, \mathrm{P}=0.19\right)$ for any

184 host species (plant species vs. restoration treatment interaction: $\mathrm{F}_{(12,36)}=1.03, \mathrm{P}=0.45$ ). Leaf

185 damage did not correlate with caterpillar abundance per plant $(\mathrm{r}=0.003, \mathrm{P}=0.96)$ or total

186 caterpillar abundance per plant species $(\mathrm{r}=0.56, \mathrm{P}=0.14)$.

187 Caterpillar predation

188 During the 2015 rainy season, a total of 2376 caterpillar clay models were exposed to predation

189 in the restoration plots, of which 352 (14.8\%) presented marks suggesting some type of predation

190 (see Supplementary material 2 for examples) and 359 (15.1\%) disappeared during the

191 experiment. Caterpillar predation on different host species ranged from 16\% (in Cordia

192 eleagnoides) to $9 \%$ (in Gliricidia sepium) but because the variance was high in all species we

193 found no statistical differences across plant species $\left(\mathrm{F}_{(8,39)}=0.656, \mathrm{P}=0.72\right.$; Fig. 4). Caterpillar

194 predation was greater on trees growing in the control treatment $\left(56 \%\right.$ vs $44 \% ; \mathrm{F}_{(1,132)}=3.95, \mathrm{P}=$

195 0.048). Also, predation during the rainy season was different between months, in both control and 
196 mulching treatment plots the percentage of predated caterpillars was lower in July ( 3 and $2 \%$,

197 respectively) than later during the rainy season (13\% in October for control plots and 10\% in

198 August for mulching treatment plots; $\mathrm{F}_{(1,132)}=4.71, \mathrm{P}=0.03$; Fig. 5a).

199 We found that color of artificial caterpillar clay models affected predation rates, where green

200 models were more predated (56\%) than brown-yellow ones $\left(44 \% ; \mathrm{F}_{(1,132)}=7.31, \mathrm{P}=0.007\right)$,

201 irrespective of host species $\left(\mathrm{F}_{(8,132)}=0.129, \mathrm{P}=0.997\right)$ or restoration treatments $\left(\mathrm{F}_{(1,132)}=0.277, \mathrm{P}\right.$

$202=0.59$; Fig. 5b).

203 When analyzing the predator type attacking caterpillar clay models, we distinguished two general

204 predation marks: 1) beak marks imposed by birds and, 2) marks imposed by invertebrates

205 characterized by small holes or small scrapes presumably made by mandibles (Suppl. Material 2).

206 Marks attributed to invertebrate predation were significantly more frequent than marks caused by

207 bird predation $\left(9.7 \%\right.$ vs. $5 \%$ of predated caterpillars, respectively; $\left.\mathrm{F}_{(1,6)}=40.41, \mathrm{P}=0.0007\right)$.

208 Temporal trends of bird and invertebrate predation marks showed different patterns, with bird

209 predation being more important in August, while invertebrate peak predation was in September

210 (month vs. predator type interaction: $\mathrm{F}_{(3,6)}=10.059, \mathrm{P}=0.009$; Fig. 6). Both types of predators

211 marks were greater on green caterpillars but the difference between colors was more pronounced

212 for bird predation marks (predator type vs. caterpillar color interaction: $\mathrm{F}_{(1,6)}=8.69, \mathrm{P}=0.025$ ).

213 Discussion

214 This study corroborated the importance of plant host identity for the recovery of caterpillar

215 populations in restoration efforts. Even though plant species showed differences in performance

216 depending on the restoration treatment applied in the site (Saucedo-Morquecho 2016),

217 lepidopteran species were not responsive to restoration treatments, but showed large differences

218 among host plant species in terms of richness and abundance. This finding is similar to other

219 studies that have found that lepidopteran communities are strongly determined by host species

220 identity irrespective of land use history (Hernández et al. 2014, Juan-Baeza et al. 2015).

221 Lepidopteran association with particular plant species is dictated by plant nutritional quality,

222 plant appearance and by predation experienced in particular plants. In particular, plant nutritional

223 quality has been associated with nutrient concentration, secondary metabolites and physical

224 defenses (thickness, trichomes and waxes) (Dyer et al. 2007). These characteristics are known to 
225 vary not only among species but also across sites (Pennings et al. 2001, Boege and Dirzo 2004).

226 However, because we did not assess these traits, further studies are needed to test how they may

227 have influenced the herbivore communities.

228 Leaf area removed by herbivores followed the same pattern observed in lepidopteran diversity,

229 some tree species had greater damage than others (in particular G. sepium showed the highest

230 percent of leaf area consumed). Since we did not find a significant correlation between

231 lepidopteran abundance and leaf damage in individual plants or at the species level, it is possible

232 that the observed damage can be due to other herbivores such as coleopteran larvae, grasshoppers

233 or ants, which are known to be important herbivores in Chamela TDF; this hypothesis also

234 warrants further investigation. Interestingly, herbivore damage levels found in this study are

235 similar to previous investigations in the region concentrated in conserved forests (Dirzo and

236 Boege 2008). Hence, we conclude that our restoration plots attracted herbivores with similar

237 ecological functions to those found in mature forests (i.e., similar pressures on plants due to leaf

238 consumption), and herbivores are not increasing their abundance in a disproportionate way

239 behaving as pests. This finding is particularly relevant, since it has been suggested that

240 restoration efforts may concentrate resources for herbivores and plants can fail to establish

241 because of increased herbivore pressure (King and Keeland 1999, Blanco-García and Lindig-

242 Cisneros 2005, Sweeney et al. 2007). In our case, leaf damage was not exacerbated and plants

243 were not particularly affected therefore, the restoration efforts where not hampered by herbivores.

244 Our results showed a very high lepidopteran species turnover between restoration treatments and 245 also between plant species. This result mirrors the lepidopteran beta diversity characteristic of 246 Mexican TDFs (López-Carretero 2010, López-Carretero et al. 2014). Due to this high diversity

247 TDFs represent a challenge for ecological conservation and restoration, hence we recommend

248 ensuring high plant diversity and heterogeneity in lepidopteran conservation/restoration 249 programs.

250 Lepidopteran predation

251 Caterpillar clay models were useful to measure lepidopteran predation by birds and invertebrates

252 in the restoration experiments. We were able to infer that invertebrate predation was stronger than

253 bird predation for caterpillars irrespective of color or plant species. Richards and Coley (2007)

254 and Suzuki and Sakurai (2015) with the same methodology also reported that invertebrates are 
255 the main predators in a tropical rainforest in Costa Rica and in Japan, respectively. However, Sam 256 et al (2015) in Papua New Guinee showed that the predator guild changed across an altitudinal

257 gradient, where birds were more important at high altitudes and ants were more important at low 258 altitudes.

259 We predicted that caterpillar predation should differ among host species due to differences in 260 canopy cover, height and structure. Other studies investigating insectivorous bird visitation rates

261 to tree species have found that they prefer certain species, in particular the ones with greater 262 insect abundance (Gantz et al. 2015) or with higher canopies (Fink et al. 2009) however, it is 263 likely that young saplings planted at the same time in our experiment did not have pronounced 264 architectural differences yet and this may have obscured possible predator preferences. Further 265 investigation is needed to understand the relative importance of predation for herbivory at a plant 266 community level, since we measured herbivory and predation rates in different years.

267 Conclusions

268 This study concurs with previous restoration experiences in that restoring TDF is a viable option

269 to recover biodiversity and highlights the importance of including a diverse community of plants

270 to enhance biodiversity recovery. Although restoration treatments did influence plant growth

271 (Saucedo-Morquecho 2016), they did not scale-up to influence lepidopteran communities and 272 predation rates. Hence, the reestablishment of ecological functions was independent of initial 273 restoration treatment. It appears that once plants are established, if the restoration outcome is 274 close to a conserved forest, as is the case in this study, herbivores and predators are able to 275 colonize and resume biotic interactions. In this context, we suggest the use of the most 276 economical option for future restoration efforts.

277 Acknowledgments

278 We are grateful to Manuel Valdes, Lenin Machuca, Nallely Luviano, Juan Pablo Martínez and

279 Gustavo Verduzco for their expert field assistance. The authors gratefully acknowledge logistical 280 support from Wolfgang Hahn and Ari Nieto, the staff of the Chamela Biological Station 281 (UNAM). 
282

283

284

285

286

287

288

289

290

291

292

293

294

295

296

297

298

299

300

301

302

303

304

305

306

307

308

309

310

311

312

313

314

315

316

317

318

319

320

321

322

323

324

325

326

327

328

Literature

Aide, M., J. K. Zimmerman, J. B. Pascarella, L. Rivera, and H. Marcano-Vega. 2000. Forest regeneration in a chronosequence of tropical abandoned pastures: implications for restoration ecology. Restoration Ecology 8:328-338.

Barajas-Guzmán, M. G. and V. L. Barradas. 2011. Microclimate and sampling survival under organic and polyethylene mulch in a tropical dry deciduous forest. Boletín de la Sociedad Botánica de México 88:27-34.

Blanco-García, A. and R. Lindig-Cisneros. 2005. Incorporating Restoration in Sustainable Forestry Management: Using Pine-Bark Mulch to Improve Native Species Establishment on TephraDeposits. Restoration Ecology 13:703-709.

Boege, K. and R. Dirzo. 2004. Intraspecific variation in growth, defense and herbivory in Dialium guianense (Caesalpiniaceae) mediated by edaphic heterogeneity. Plant Ecology 175:59-69.

Burgos, A. and J. M. Maass. 2004. Vegetation change associated with land-use in tropical dry forest areas of Western Mexico. Agriculture Ecosystems and Environment 104:475-481.

Ceccon, E., J. I. Barrera-Cataño, J. Aronson, and C. Martínez-Garza. 2015. The socioecological complexity of ecological restoration in Mexico. Restoration Ecology 23:331-336.

Chalker-Scott, L. 2007. Viewpoint impact of mulches on landscape plants and the environment — a review. Journal of Environmental Horticulture 25:239-249.

Dirzo, R. and K. Boege. 2008. Patterns of herbivory and defense in tropical dry and rain forests. Pages 63-78 in W. P. Carson and S. A. Schnitzer, editors. Tropical forest community ecology. Blackwell Publishing Oxford.

Dyer, L. A., M. S. Singer, J. T. Lill, J. O. I. Stireman, G. L. Gentry, R. Marquis, R. E. Ricklefs, H. F. Greeney, D. L. Wagner, H. C. Morais, I. R. Diniz, T. A. Kursar, and P. D. Coley. 2007. Host specificity of Lepidoptera in tropical and temperate forests. Nature 448:696-700.

Fink, R. D., C. A. Lindell, E. B. Morrison, R. A. Zahawi, and K. D. Holl. 2009. Patch Size and Tree Species Influence the Number and Duration of Bird Visits in Forest Restoration Plots in Southern Costa Rica. Restoration Ecology 17:479-486.

Gantz, A., M. Yañez, J. I. Orellana, S. Sade, and C. E. Valdivia. 2015. Use of tree species by White-throated treerunner (Pygarrhichas albogularis King) in a secondary native forest of southern Chile. Iheringia 105:193-198.

García-Oliva, F., A. Camou, and J. M. Maass. 2002. El clima de la región central de la costa del Pacífico mexicano.in A. N. Noguera-Alderte, J. H. Vega-Rivera, A. N. Garcia-Aldrete, and M. Quesada, editors. Historia natural de Chamela. Instituto de Biología-UNAM, México DF.

Gonzáez-Iturbe, J. A., I. Olmsted, and F. Tun-Dzu. 2002. Tropical dry recovery after longterm Henequen (sisal, Agave fourcroydes Lem.) plantation in northern Yucatan, Mexico. Forest Ecology and Management 167:67-82.

Haber, W. A. and G. W. Frankie. 1989. A Tropical Hawkmoth Community: Costa Rican Dry Forest Sphingidae. Biotropica 21:155-172.

Hernández, Y., K. Boege, R. Lindig-Cisneros, and E. del-Val. 2014. Are ecological processes reestablished after restoration? A comparison of herbivory rates and herbivore communities in a restored vs. Successional site of a tropical dry forest. Southwestern Naturalist 59:68-76.

Howe, H. F. and C. Martínez-Garza. 2014. Restoration as experiment. Botanical Sciences 92.

Jones, M. E. and N. Davidson. 2016. Applying an animal-centric approach to improve ecological restoration. Restoration Ecology. 
329

330

331

332

333

334

335

336

337

338

339

340

341

342

343

344

345

346

347

348

349

350

351

352

353

354

355

356

357

358

359

360

361

362

363

364

365

366

367

368

369

370

371

372

373

374

375

376

Juan-Baeza, I. B., C. Martínez-Garza, and E. del-Val. 2015. Recovering More than Tree Cover: Herbivores and Herbivory in a Restored Tropical Dry Forest. PloS ONE 10:e0128583.

King, S. L. and B. D. Keeland. 1999. Evaluation of reforestation in the lower Mississippi river alluvial valley. Restoration Ecology 7:348-359.

Lebrija-Trejos, E., J. A. MEave, L. Poorter, E. A. Pérez-García, and F. Bongers. 2008. Pathways, mechanism and predictability of vegetation change during tropical dry forest succession. Perspectives in Plant Ecology, Evolution and Systematics 12:267-275.

López-Carretero, A. 2010. Composición y diversidad de lepidópteros en la cronosecuencia sucesional del bosque tropical caducifolio, consecuencias sobre la herbivoría de Casearia nitida. UNAM, Mexico DF.

López-Carretero, A., C. Díaz-Castelazo, K. Boege, and V.-. Rico-Gray. 2014. Evaluating the Spatio-Temporal Factors that Structure Network Parameters of Plant-Herbivore Interactions. PloS ONE 9:e110430.

Lott, E. J., S. H. Bullock, and J. A. Solís-Magallanes. 1987. Floristic diversity and structure of upland and arroyo forests in coastal Jalisco. Biotropica 19:228-235.

Murphy, P. G. and A. E. Lugo. 1986. Ecology of tropical dry forest. Annual Review of Ecology and Systematics 17:67-88.

Noguera, F. A., J. H. Vega-Rivera, A. N. García-Alderete, and M. Quesada. 2002. Historia natural de Chamela. Instituto de Biología, UNAM, México, D.F.

Noreika, N., J. S. Kotiaho, J. Penttinen, P. Punttila, A. Vuori, T. Pajunen, O. Autio, O. J. Laukola, and D. Johan Kotze. 2015. Rapid recovery of invertebrate communities after ecological restoration of boreal mires. Restoration Ecology 23:566-579.

Novotny, V., Y. Basset, S. E. Miller, R. L. Kitching, M. Laidlaw, P. Drozd, and L. Cizek. 2004. Local species richness of leaf-chewing insects feeding on woody plants one hectare of a lowland rainforest. Conservation Biology 18:227-237.

Novotny, V., Y. Basset, S. E. Miller, G. D. Weilblen, B. Bremer, L. Cizek, and P. Dorozd. 2002. Low host specificity of herbivorous insects in a tropical forest. Nature 416:841-844.

Novotny, V., P. Drozd, S. E. Miller, M. Kulfan, M. Janda, Y. Basset, and G. D. Weilblen. 2006. Why are there so many species of herbivorous insects in tropical rainforests? Science 313:1115-1118.

Pennings, S. C., E. L. Siska, and M. D. Bertness. 2001. Latitudinal differencesin plant palatability in the Atlantic coast Salt Marshes. Ecology 82:1344-1359.

Pescador-Rubio, A., A. Rodríguez-Palafox, and F. A. Noguera. 2002. Diversidad y estacionalidad de Arthropoda.in A. N. Noguera-Alderte, J. H. Vega-Rivera, and M. Quesada, editors. Historia natural de Chamela. Insituto de Biología, UNAM, Mexico DF.

Richards, L. A. and P. D. Coley. 2007. Seasonal and habitat differences affect the impact of food and predation on herbivores: a comparison between gaps and understory of a tropical forest. Oikos 116:31-40.

Sam, K., B. Koane, and V. Novotny. 2015. Herbivore damage increases avian and ant predation of caterpillars on trees along a complete elevational forest gradient in Papua New Guinea. Ecography 38:293-300.

Sánchez-Azofeifa, G. A., M. Quesada, P. Cuevas-Reyes, A. Castillo, and G. Sánchez-Montoya. 2009. Land cover and conservation in the area of influence of the Chamela-Cuixmala Biosphera Reserve, Mexico. Forest Ecology and Management 258:907-912.

Sánchez-Azofeifa, G. A., M. Quesada, J. P. Rodríguez, J. M. Nasar, K. E. Stoner, A. Castillo, T. Garvine, E. L. Zent, J. Calvo-Alvarado, M. Kalacska, L. Fajardo, J. A. Gamon, and P. Cuevas-Reyes. 2005. Research Priorities for Neotropical Dry Forests. Biotropica 37:477485. 
377 Saucedo-Morquecho, E. 2016. Desempeño y atributos funcionales de árboles en plantaciones de restauración ecológica en el bosque tropical caducifolio de chamela, Jalisco. UNAM, México DF.

SER. 2007. Principios de SER Internacional sobre la Restauración Ecológica. Society for Ecological Restoration International, USA.

Suzuki, T. N. and R. Sakurai. 2015. Bent posture improves the protective value of bird dropping masquerading by caterpillars. Animal Behaviour 105:79-84.

Sweeney, B. W., S. J. Czapka, and C. A. Petrow. 2007. How planting method, weed abatement, and herbivory affect afforestation success. Southern Journal of Applied Forestry 31:85-97.

Trejo, I. and R. Dirzo. 2000. Deforestation of seasonally dry tropical forest: a national and local analysis in Mexico. Biological Conservation 94:133-142.

389

Tvardikova, K. and V. Novotny. 2012. Predation on exposed and leaf-rolling artificial caterpillars in tropical forest of Papua New Guinea. Journal of Tropical Ecology 28:331-341. 


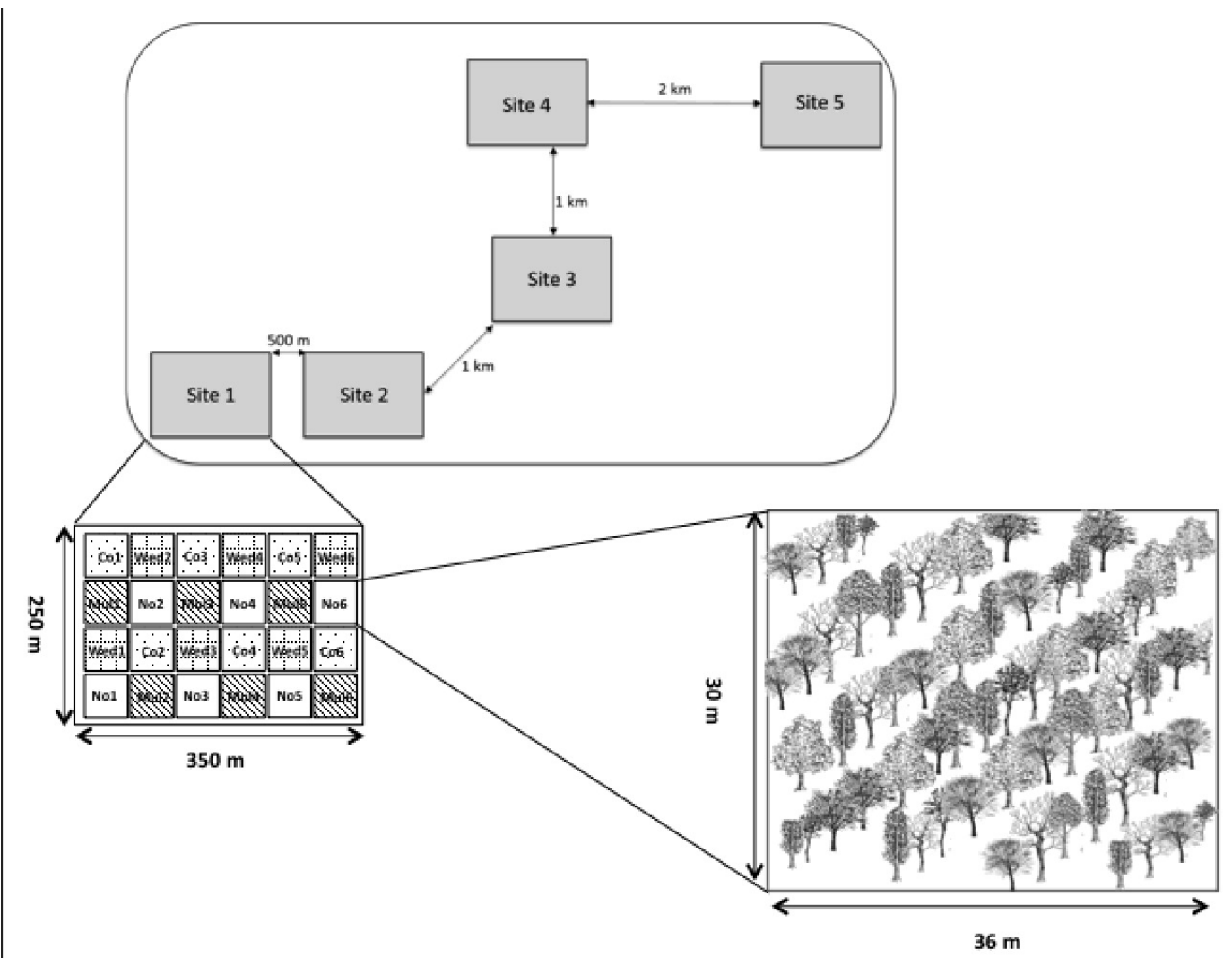

390 Figure 1. Experimental set-up showing different experimental sites and restoration plots inside

391 each site. Restoration code treatments are as follows: Co, control with planting; $\mathrm{Mu}$, planting 392 with plastic mulching; Wed, planting with weeding; No, control with natural regeneration. Note 393 that in this article we only report results from the $\mathrm{Co}, \mathrm{Mu}$ and Wed restoration treatments. 


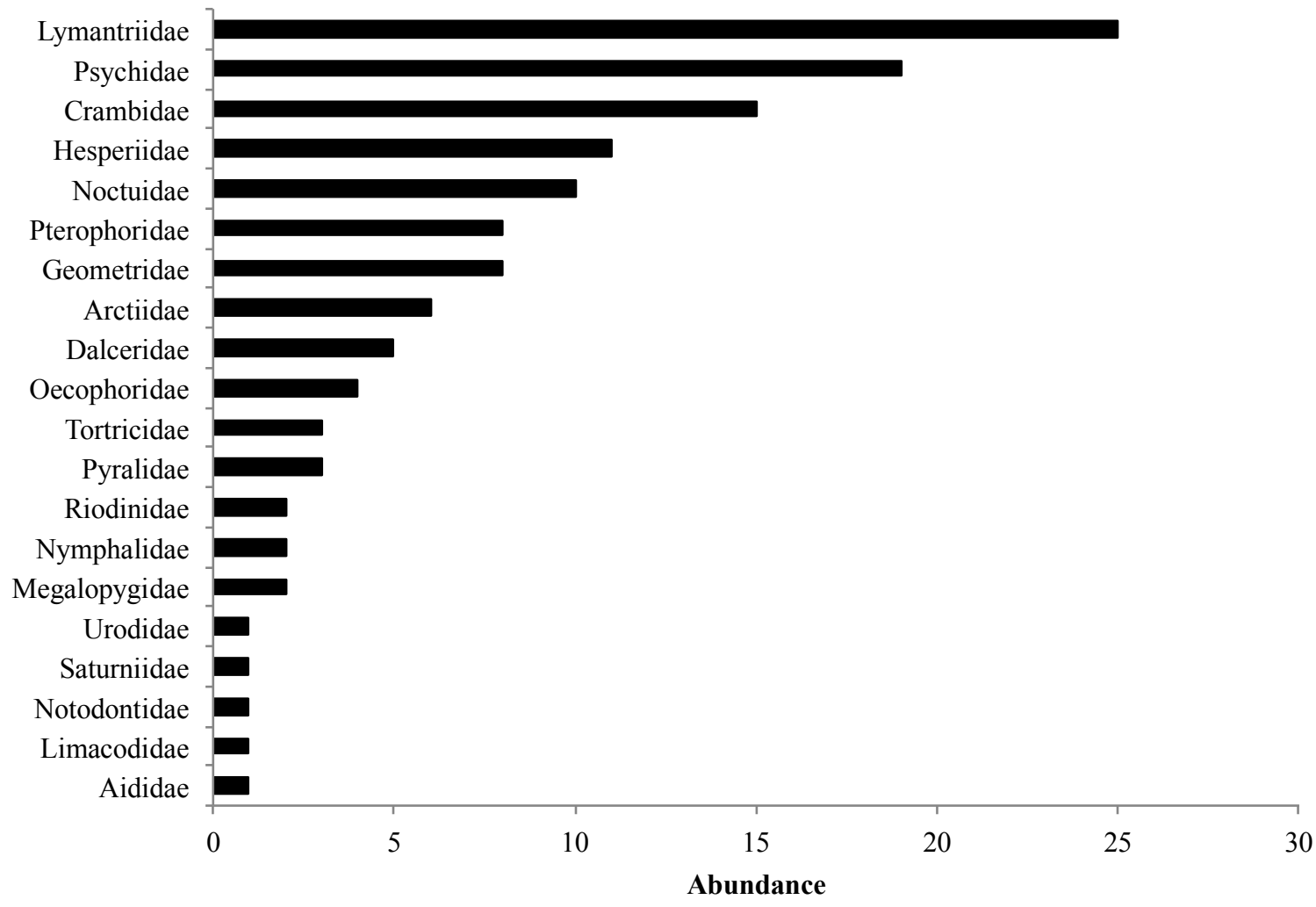

394 Figure 2. Total caterpillar abundance per family including all restoration treatments. 


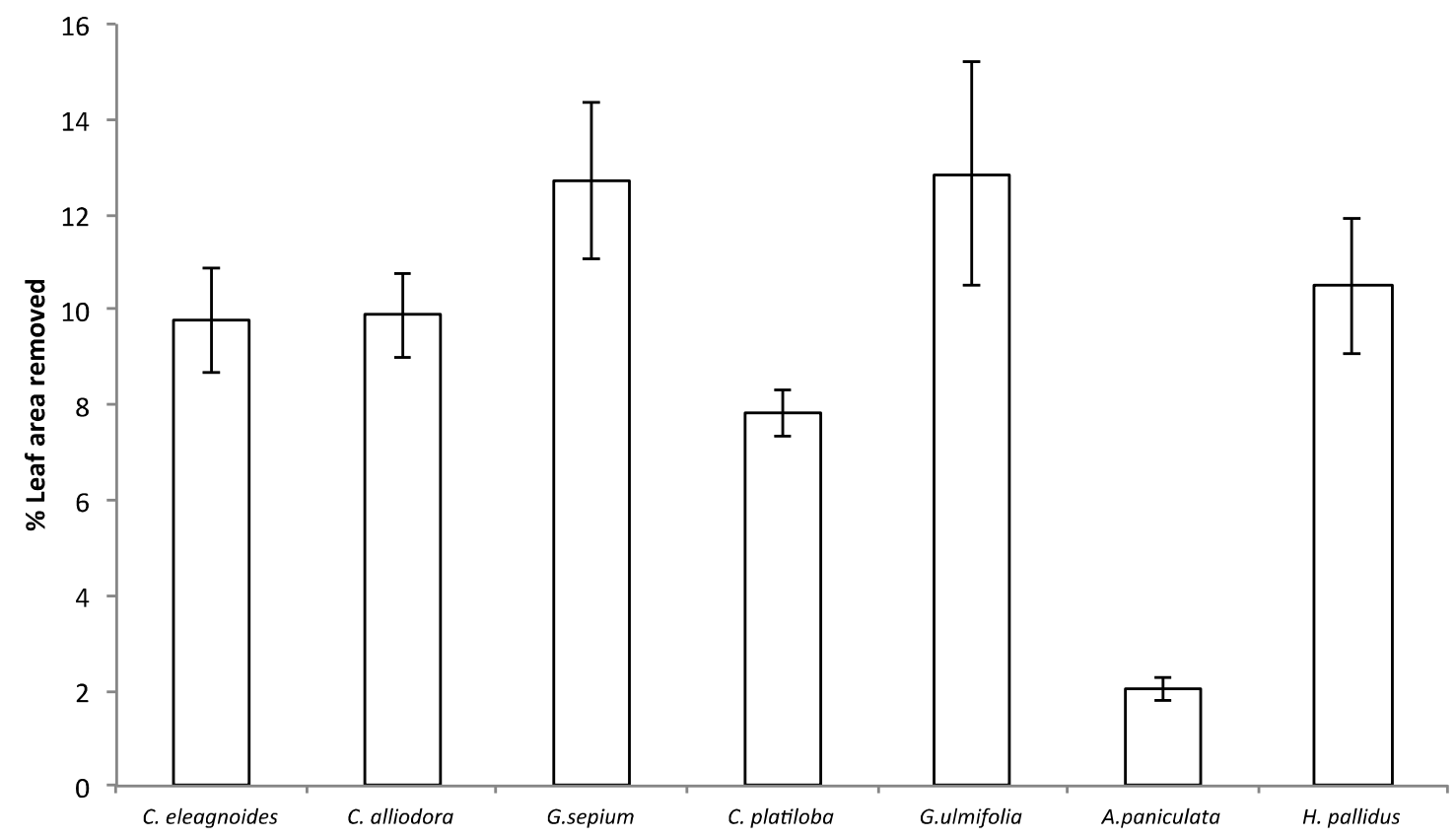

395 Figure 3. Percent leaf area removed (Mean \pm EE) in trees, averaged across all restoration 396 treatments in the TDF, $\mathrm{F}_{(6,36)}=22.7, \mathrm{P}<0.001$. 


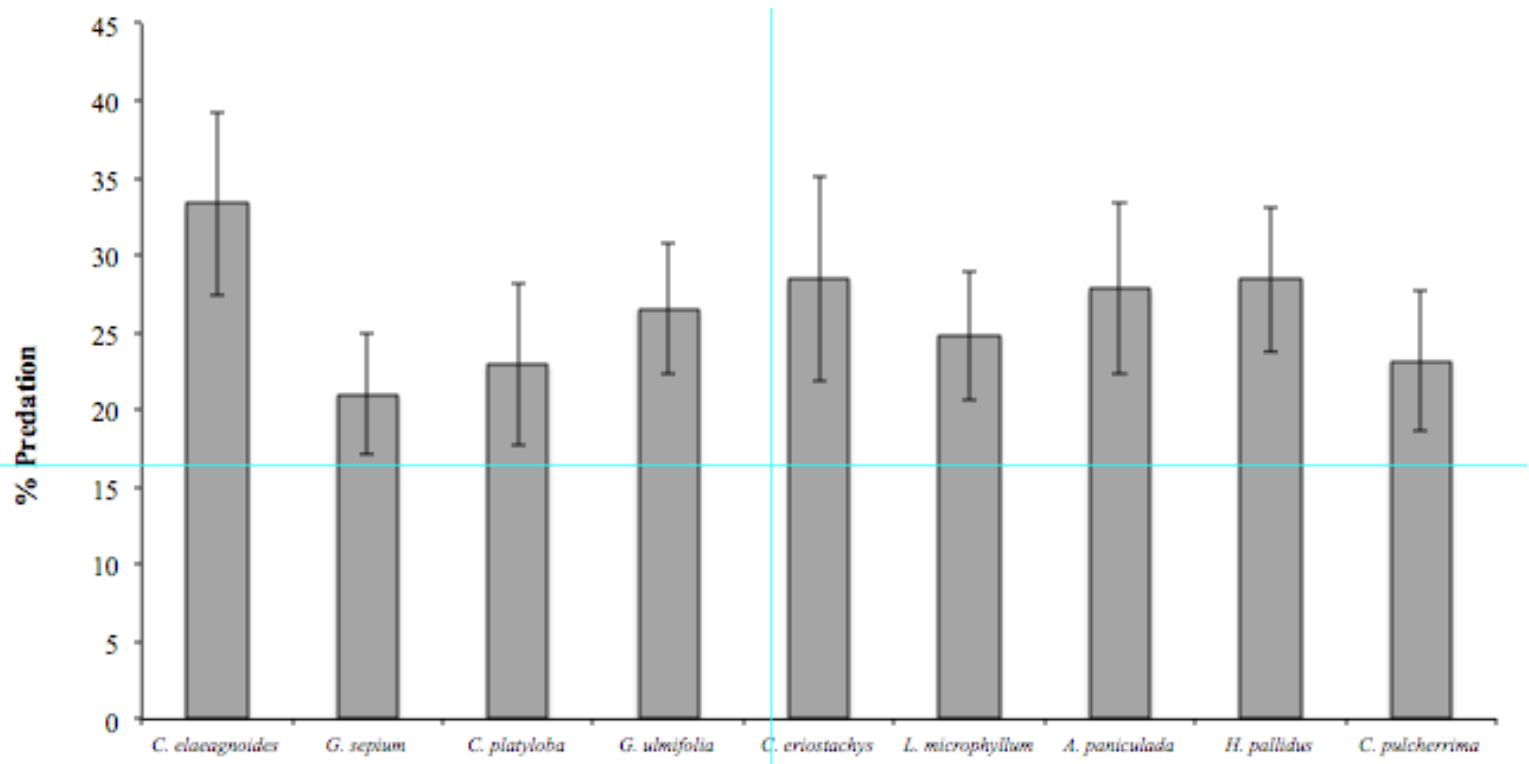

397 Figure 4. Percent predation on clay models (Mean \pm SE) associated with different plant species 398 during the rainy season of $2015, \mathrm{~F}_{(8,39)}=0.656, \mathrm{P}=0.72$. 


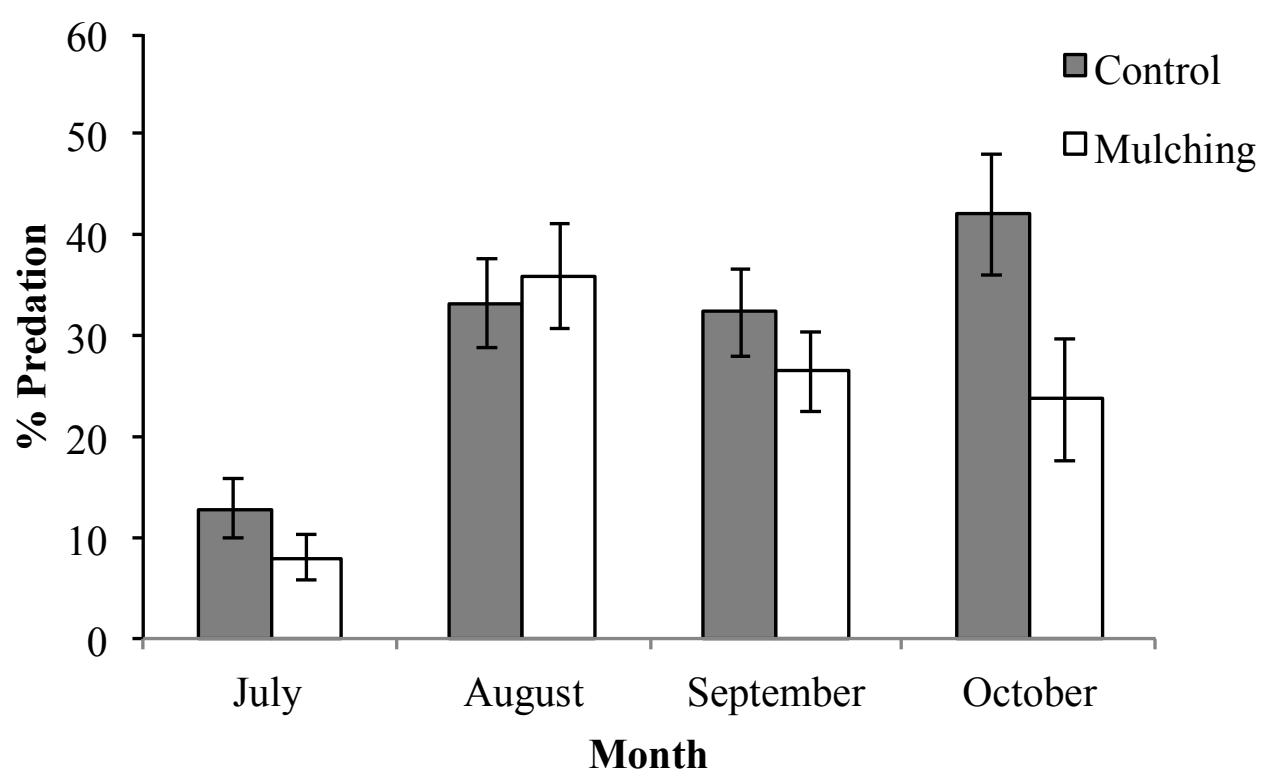

$400 \quad 5 b$

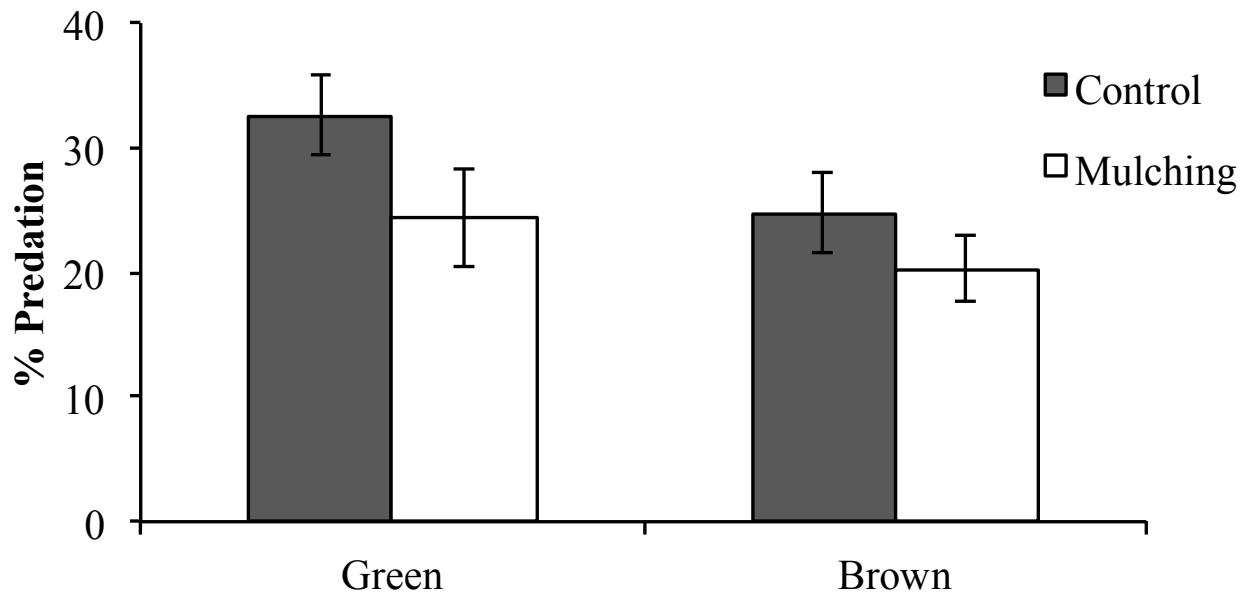

Color

401 Figure 5. Percent predation on caterpillar clay models (Mean \pm SE) during the rainy season of 402 2015: a) in the control and mulching restoration sites, month vs. predator type interaction: $\mathrm{F}$ $403(3,6)=10.059, \mathrm{P}=0.009, \mathrm{~b})$ on green and brown caterpillar clay models (Mean $\pm \mathrm{SE}$ ) in control and 404 mulching restoration treatments 


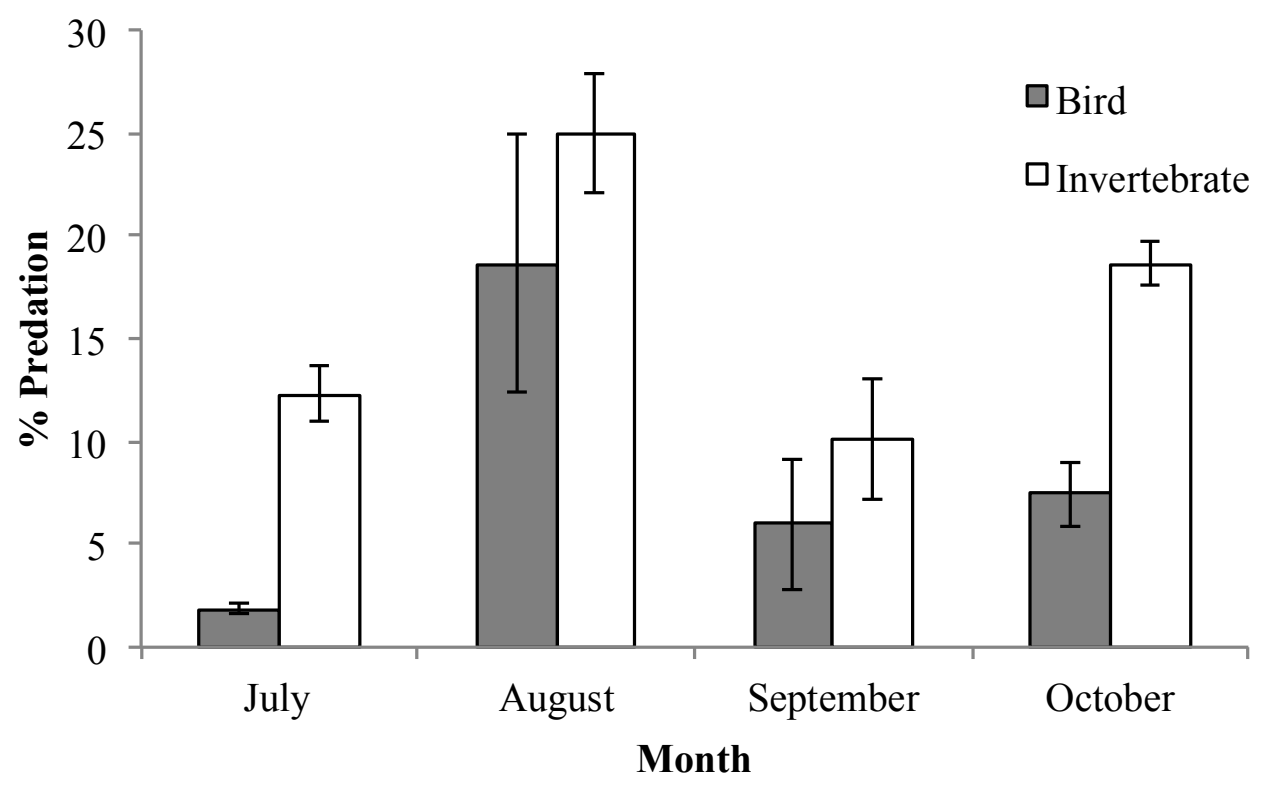

405 Figure 6. Percent predation caterpillar clay models (Mean \pm SD) per guild type (bird or 406 invertebrate) during the rainy season of 2015. 
407 Table 1. Number of unique (diagonal shadowed) and shared (below the diagonal) Lepidopteran 408 species between restoration treatments.

\begin{tabular}{|llll|}
\hline & Weeding & Mulching & Control \\
Weeding & $\mathbf{1 4}$ & & \\
Mulching & 14 & $\mathbf{1 0}$ & \\
Control & 19 & 10 & $\mathbf{1 1}$ \\
\hline
\end{tabular}


409 Table 2. Bray-Curtis dissimilarity index between Lepidopteran species associated to different 410 plant species

C. alliodora
G. sepium
C. platyloba
G. ulimifolia
L. leucocephala
C. eriostachys
A. paniculata
H. pallidus
C. pulcherrima
L. microphyllum

C. eleagnoides
0.93939 0.90804 0.91836

0.87301

0.958333

0.958333
0.937500

0.894736

0.869565

0.941176

0.942857

C.
alliodora

0.97058
0.93333
0.95454
1.000000
1.000000
0.894736
1.000000
0.866667
0.875000

G. sepium

C. platyloba

G. ulimifolia

0.92857

0.69387

0.69387
0.83132

0.82089

0.78082

0.92592

0.97101

0.97143

$$
\begin{aligned}
& 0.700000 \\
& 0.955555 \\
& 0.931034 \\
& 0.942857 \\
& 0.860465 \\
& 0.870967 \\
& 0.87500
\end{aligned}
$$

0.7966

0.8139

0.6326

0.8596

0.8666

0.8695
0.555556

1.000000

1.000000

1.00000
L. leucocephala

C. eriostachys

A. paniculata

H. pallidus

0.6428
0.7058
0.95238
0.73333
0.93548

0.95238

0.93548
0.9375

$0.9000 \quad 1.0000$


